The lettering, as often in medical prescriptions and labels in chemists' shops, is intentionally cabalistic, partly Greek and partly Latin, mixed and varied and sometimes reversed : thus $p$ and $s$ reversed, $\mathrm{n}$ reversed, e a Greek capital, $\mathrm{m}$ Greek small and reversed. To the ignorant purchaser no doubt the Abracadabra style would add much to the efficacy of the ointment. As noted by Mr. James, an oculist's stamp in Samian ware is recorded in the British Museum Guide to Roman Britain, p. 34.

I am, yours faithfully,

Christ's Hosptral,

S. E. Winbolt, M.A.

West Horsham.

\title{
SPONTANEOUS ABSORPTION OF MATURE SENILE CATARACT
}

\section{To the Editor of The Britrsil Journal of Ophthalmology}

SiR,- - I suggest that the lens described by Mr. Ballantyne in the April issue of the British Journal of Ophthalmology, pp. 202-3, represents the ultra-Morgagnian phase of senile cataract, but with the remains of the nucleus more transparent and perhaps thinner than usual. This phase was seen not infrequently in India.

Though present only in a minority of the cases the "numerous fine white spots" mentioned are characteristic of Morgagnian cataract, and of the final stage, with all the "milk" absorbed, leaving only the nucleus, more or less reduced in size in an otherwise empty capsule. The nuclear remains have the flat anterior surface and curved posterior surface mentioned by Mr. Ballantyne. The white dots are capsular, limited almost entirely to the anterior capsule, which is thickened. The clinical description was given in my book on "Cataract Extraction," 1908, and the minute anatomy in the Trans. Ophthal. Soc., U.K., Vol. XXXV (1915), pp. 349-53.

With the ultra-Morgagnian cataract more or less tremor of the iris is usually, if not always, present. If this escapes notice, in the cases without capsular opacities the semi-transparent nucleus may look exactly like the lens in the unripe stage of cataract of the dry shrinking type. Thus occasionally in Bombay the true condition was not recognized until the iridectomy was made in the combined extraction operation, showing a black coloboma above the upper edge of the small nucleus. Dilatation of the pupil in Mr. Ballantyne's case should in the same way readily 
show the upper margin of the thin nucleus, but not its lower margin, which lies at the bottom of the loose capsule.

Yours truly,

H. HERBERT,

L.t.-Col., I.M.S. (Retd.)

\section{NOTES}

Death

WE regret to record the death, on April 2, Harrogate Infirmary. of Mr. Charles Ernest Pronger, of Harrogate, Consulting Ophthalmic Surgeon to the

After considerable experience in general surgery in North Devon, he decided to specialize in ophthalmology, and rapidly became well known, especially in the north, for his work. He was one of the first to emphasize the importance with regard to the general health of the correction of small errors of refraction.

Mr. Adrian Caddy has been appointed Appointment Assistant Surgeon to the Royal Westminster Ophthalmic Hospital.

IN abstract No. 13, March, 1926, page 162 , Corrigenda Dr. Verhoeff writes to point out that he does not dismiss the factor of diminished lacrymal secretion as a cause of neuro-paralytic keratitis.

Sir Alexander Lawrence writes to say that M. Esperandieu's reading of the first two letters of the Lansdowne stamp, page 130, is $F_{L}$, Flavius.

Lieut.-Colonel A. E. J. Lister writes to say that in 1913 Professor F. Dimmer was in charge of the First Eye Clinic in Vienna, v. page 303 .

\section{FUTURE ARRANGEMENTS}

\section{6}

June 11. - Royal Society of Medicine, Section of Ophthalmology (Annual).

July 14-17.-Oxford Ophthalmological Congress. July 21-23.-British Medical Association at Nottingham. 